\title{
Emergency Trolley's Contents and Records: Audit Study at Maternity Sections, State Hospitals, Windhoek, Namibia
}

\author{
Benjamin Klaas Sebulon Manetti, Hans Justus Amukugo, Anna Panduleni Kauko Shilunga \\ Department of General Nursing Science, School of Nursing, University of Namibia, Windhoek, Namibia \\ Email: hamukugo@unam.na
}

How to cite this paper: Manetti, B.K.S., Amukugo, H.J. and Shilunga, A.P.K. (2018) Emergency Trolley's Contents and Records: Audit Study at Maternity Sections, State Hospitals, Windhoek, Namibia. Open Journal of Nursing, 8, 448-472.

https://doi.org/10.4236/ojn.2018.87035

Received: April 8, 2018

Accepted: July 15, 2018

Published: July 18, 2018

Copyright (c) 2018 by authors and Scientific Research Publishing Inc. This work is licensed under the Creative Commons Attribution International License (CC BY 4.0).

http://creativecommons.org/licenses/by/4.0/

\begin{abstract}
The purpose of the study sought to assess and evaluate the contents and records of the emergency trolley in the maternity section of the state hospitals in Windhoek, Namibia. A quantitative and descriptive research design was used for the study to investigate emergency equipment, essential drugs and emergency trolleys. A convenient sample of 10 emergency trolleys in the Windhoek Central Hospital (Hospital A) and Katutura Intermediate Hospital (Hospital B) in Windhoek, Namibia were used. Data was collected using a checklist adapted and edited from the EMSSA. Data were analysed using Microsoft excel 2013. Essential paediatric equipment including bag valve mask devices, Magill's forceps, oxygen masks were absent in many of the units and wards. Data described that checking of defibrillators, monitors and suction devices still remained a major problem in the units/wards that were fortunate enough to have the aforementioned equipment. A conclusion was that generally the units/wards performed well during the assessments and evaluations. There were still units without emergency trolleys, trolleys that were poorly assessed, and those that were obstructed and registered nurses that had a negative perception to the audit of the emergency trolley. Specialized units such as NICU and Hi-Care Hospital A and Prem Unit Hospital B performed very well in their assessments. Development of policy with regards to assessing, restocking and maintenance of emergency supplies can be used to guide the nurses on what to do. Resuscitation morbidity and mortality meetings in order to identify issues and outcomes surround resuscitation incidences within the unit or ward.
\end{abstract}

\section{Keywords}

Audit, Emergency Trolley, Contents, Records, Maternity Section, State 
Hospitals, Windhoek, Namibia

\section{Introduction}

In-hospital cardiopulmonary arrest requires an immediate response to increase the likelihood of a successful outcome. Most cardiac arrests are sudden and unexpected occurrences, requiring immediate actions. Successful CPR relies on the availability and correct functioning of essential resuscitation equipment and recommended drugs available from a well-equipped resuscitation trolley, as well as on skilled personnel [1]. The Emergency Medicine Society of South Africa has published a document known as Practice Guideline EM006, Resuscitation Trolley Equipment in general practice areas, in-hospital wards, clinics and other non-emergency areas which set out the minimum recommended contents of the emergency trolley for areas of the hospitals other than casualty [2]. A relevant registered nurse (RN) should be assigned responsibility for checking the resuscitation (emergency) trolley (at least) daily. The relevant registered nurse should document the check of the resuscitation trolley onto the Resuscitation (Emergency) Trolley Contents and Layout Checklist. The checklist of resuscitation (emergency) trolley should be regularly audited by District Clinical Governance Units or in the case of Namibian state hospitals, by a matron to ensure both compliance with the need for a (minimum) daily checking schedule and the basic standardisation is being maintained [3].

A study conducted on factors affecting the quality of pulmonary resuscitation in in-patient units: perception of nurses found that in the perception of nurses, the high number of professionals during CPR lack of material and/or equipment failure (57.1\%), and lack of familiarization with the emergency trolley (98.0\%) interfere in the quality of CPR performed on patients in the inpatient unit [4]. State Hospital Maternity Sections in Windhoek are the recommended and preferred places of care for women in the prenatal, intra-natal and postnatal care seeking maternity care in the public health care system. There are cases that arise in any of these stages that require emergency services thus require immediate or urgent care, with some of these cases being those of neonates. Katutura State Hospital is a hospital in Katutura, a black township of Windhoek, Namibia, together with the Windhoek Central Hospital [5]. It is one of two State Hospitals in the Windhoek area and Namibia's only general referral hospital. Windhoek Central Hospital is the only specialist tertiary public hospital in Namibia. Together with the Katutura State Hospital, it is one of two State Hospitals in Windhoek and serves a population of 400,000 residents in the city of Windhoek [5]. In order to improve resuscitation outcomes an effective resuscitation response or strategy is needed and this includes the availability of appropriate resources for services to function effectively. Nurses are the backbone of the health sector and thus manage various aspects of the health care sector. As such they are expected to react during an emergency situation. This can only happen if 
there is appropriate and sufficient availability of emergency resuscitation equipment such as the emergency trolley. Nurses are tasked with making sure that the emergency trolley is in a good working order and that all drugs and equipment are available and up to standard. A study was conducted to audit the emergency trolley's contents and records in the maternity section of the state hospitals in Windhoek. This audit involved evaluating the availability of essential emergency drugs, whether they were expired or whether the quantity expected was available in the trolley. This was done using a checklist of the various drugs that were expected to be in the emergency trolley. It also involved evaluating the availability of essential equipment, whether these equipment were in working, in sterile packs and in the correct quantity. There was an assessment of the condition and functionality of the emergency trolley as to whether it was in working order, if the wheels were functioning, if the drawers could open well and whether the trolley was not in a dilapidated state.

\section{Problem Statement}

State Hospital Maternity Sections in Windhoek are the recommended and preferred places of care for women in the prenatal, intra-natal and postnatal care seeking maternity care in the public health care system. There are cases that arise in any of these stages that require emergency services thus require immediate or urgent care, with some of these cases being those of neonates. In order to improve resuscitation outcomes an effective resuscitation response or strategy is needed and this includes the availability of appropriate resources for services to function effectively. Nurses are the backbone of the health sector and thus manage various aspects of the health care sector. As such they are expected to react during an emergency situation. This can only happen if there is appropriate and sufficient availability of emergency resuscitation equipment such as the emergency trolley.

A study was conducted to audit the emergency trolley's contents and records in the maternity section of the state hospitals in Windhoek. This audit involved evaluating the availability of essential emergency drugs, whether they were expired or whether the quantity expected was available in the trolley. This was done using a checklist of the various drugs that were expected to be in the emergency trolley. It also involved evaluating the availability of essential equipment, whether these equipment were in working, in sterile packs and in the correct quantity. There was an assessment of the condition and functionality of the emergency trolley as to whether it was in working order, if the wheels were functioning, if the drawers could open well and whether the trolley was not in a dilapidated state.

\section{Purpose and Objective of the Study}

The purpose of the study was to evaluate and assess the state of the emergency trolley contents and records in the maternity sections of the state hospitals in 
Windhoek in the form of an audit while the objectives of the study were to:

1) Evaluate the availability of essential emergency equipment;

2) Evaluate the availability of essential emergency resuscitation drugs;

3) Assess the condition and functionality of the emergency trolley.

\section{Methodology}

\subsection{Design}

A quantitative, descriptive research design was used for the study to evaluate emergency equipment, essential drugs and emergency trolleys at 10 units and wards in Maternity Sections of the State Hospitals in Windhoek. The following items were audited: the contents of the emergency trolley, the functionality of the emergency trolley, the availability of essential resuscitation drugs and intravenous fluids on the emergency trolley.

\subsection{Sample of the Study}

The sample of this study comprised of the state hospitals in Windhoek, Namibia. The target and accessible population of hospitals comprised of the Hospital B and Hospital A. These two hospitals were assigned for the study as they are the only two state hospitals in Windhoek and they are the highest volume state hospitals in the country.

\subsection{Sample and Sampling Technique}

The sample was obtained from the maternity sections of the two state hospitals in Windhoek. Each hospital consists of a maternity section with 5 units/wards. Each unit/ward includes an emergency trolley, these trolley make up 10 in total representing 100\%. The emergency trolleys from ten units and wards were selected which were based in the maternity sections of the two hospitals audited. These were the Hospital A as well as the Hospital B in Windhoek. The units and wards consisted of Post Natal Block A and B, Antenatal Clinic, Prem Unit and Labour Ward at $\mathrm{KSH}$, Post Natal Ward and Post Natal Recovery Unit, Neo-Natal ICU, Antenatal Clinic and Labour Ward at Hospital A.

\subsection{Inclusion Criteria}

Inclusion criteria are characteristics that the prospective subjects must have to be included in the study [6]. Inclusion criteria for this audit were the one (1) Intermediate State hospital and one (1) Referral State Hospital in Windhoek. It included 10 units and wards namely the Katutura State Hospital Antenatal Care unit, Antenatal ward, the Post Natal ward block A and B and the premature unit. Windhoek State Hospital Antenatal care unit, Antenatal ward, Post Natal ward (including the section for post anaesthesia from labour theatre) and Neonatal ICU. The study focused on the emergency trolley, equipment and drugs. It also includes the assessment of the records of the emergency trolleys. 


\subsection{Data Collection Method}

A checklist of emergency drugs and equipment was adapted and edit from the Emergency Medicine Society of South Africa (EMSSA) guidelines was used as the audit tool to evaluate if the emergency trolley list in the maternity section complied with recommended guidelines for the type of emergency equipment, drugs and the emergency trolley available. For the purpose of conducting the audit, an adapted checklist of the drugs and equipment was used to evaluate the content of the emergency trolleys. The record of the emergency trolleys was also audited to assess whether what was ticked as being present in the trolley was there or whether it is incorrectly been ticked as being present or whether it has been left blank to indicate that the drug or equipment is not present in the trolley. It was found that the EMSSA checklist was too general and included certain emergency drugs and equipment which were not applicable or in practice in the state hospitals assessed. An example of this was nasopharyngeal airways. Items on the checklist which did not meet the criteria for the Namibian setting were omitted, which allowed the checklist to be more appropriate and still keep it valid. Drugs that were not on the checklist were also included to avoid omissions during the assessment. This allowed for the minimization of errors when assessing and thus avoiding results that were not a true reflection of the status of the emergency trolleys contents and records in the various units and wards that were assessed.

Practice Guideline of the minimum recommended contents of a resuscitation trolley, for areas of the hospital other than the Emergency Centre, or for use in general practice rooms. Essential emergency equipment, emergency drugs and intravenous fluids required on an emergency trolley.

1) Devices to open and protect airway were laryngoscope set, tracheal intubation tubes, oropharyngeal airways, nasopharyngeal airways.

2) Devices to confirm tracheal intubation were oesophageal detector device, end tidal $\mathrm{CO}_{2}$ monitoring.

3) Equipments for intubation process were introducers for ET tubes and Magill's forceps.

4) Devices to deliver oxygen and to ventilate patients were bag valve ventilation devices with oxygen reservoir, adult, paediatric and neonatal masks and oxygen delivery devices.

5) Equipments to diagnose and treat cardiac arrhythmias were ECG monitor defibrillators and cardiac arrest board.

6) Devices to gain vascular access were I.V. cannulae, needles and syringes and I.V. administration set.

7) Equipment for monitoring airway, breathing and circulation were stethoscope, pulse oximeter, thermometer, blood glucose testing, collection tubes for investigations.

8) Essential emergency drugs and intravenous solutions were adrenaline, furosemide, insulin, medical oxygen, atropine, antihistamine, magnesium and cal- 
cium chloride $10 \%$.

\subsection{Data Analysis}

The data were analysed using Microsoft Excel version 2013 computer program to generate figures, tables and graphs. A descriptive study was utilised in the form of frequency distribution summarised in the data displayed in figures and tables, expressed in percentages for comparative purposes.

\section{Ethical Consideration}

No person (other than the researcher himself) was involved in the selected units and wards of the Maternity sections of the state hospitals in Windhoek, Namibia. Permission to conduct the research was obtained from the School of Nursing and Ministry of Health and Social services. Principle of respect, justice, and beneficence was ensured.

\section{Validity and Reliability}

\subsection{Validity}

Because the checklist is from a medical body that consist of researchers, doctors, nurses and paramedics that specialises in emergency, there may be a high degree of validity of the checklist instrument, as validity is the extent to which an instrument measures what it is supposed to measure and performs as it is designed to perform. In order to test the validity of a quantitative test a pilot study can be carried out.

External validity is the extent to which the results of a study can be generalized from a sample to a population, and because this study was carried out in a state hospital, it could be generalised to a degree to other referral state hospitals as there should be a general standard in these hospitals. Content validity refers to the appropriateness of the content of an instrument [7]. In other words, do the measures (questions, observation logs, etc.) accurately assess what you want to know? This checklist contains all the minimum requirements an emergency trolley should contain and thus validates the content validity. However validity is more important than reliability. A useful instrument is both valid and reliable [7].

\subsection{Reliability}

The checklist used was constantly measuring the same variables. However, the differences were the different wards and units and that some were only paediatric or adult while others were both. However because an emergency trolley is an object that need to be constantly monitored and kept in order there should be a consistency with the results. For this study a checklist was approved by the Ministry of Health and Social Services as well as my University of Namibia research supervisor. The checklist used to audit the emergency trolleys' were based on the checklist developed by the Emergency Medicine Society of South Africa. How- 
ever, it was edit to be specific to each unit and ward. Before collecting the data, the researcher carried out a pilot study in two hospital wards that did not participate in the actual study in order to pre-test the instrument. No problems were encountered and the checklist was accepted. Similar shortcomings were noted in the emergency trolleys of both wards. Only one researcher collected all the data and completed all the audit checklists, ensuring that no inter-rater variability existed. Items on the checklist which did not meet the criteria for the Namibian setting were omitted, which allowed the checklist to be more appropriate and still keep it valid. Drugs that were not on the checklist were also included to avoid omissions during the assessment. This allowed for the minimization of errors when assessing and thus avoiding results that were not a true reflection of the status of the emergency trolleys contents and records in the various units and wards that were assessed. The research instrument was approved by my supervisor and the Ministry of health and social services.

\section{Result}

\subsection{Objective 1: Evaluate the Availability of Essential Emergency Equipment}

\subsubsection{Devices to Open and Protect the Airway}

The devices to open and protect the airway include laryngoscope set, Tracheal tubes, Water-soluble lubricant/KY Jelly, $10 \mathrm{ml}$ Syringe, Tape or equivalent to tie tube in place, oropharyngeal airways.

Ante-Natal Care Hospital B: laryngoscope set was present, no spare bulbs or batteries were available. Tracheal tubes: $4(33.33 \%)$ items were available which sizes were $2.5 \mathrm{~mm}$ and $3.5 \mathrm{~mm}$ uncuffed et tubes and $7.0 \mathrm{~mm}, 7.5 \mathrm{~mm}$ cuffed et tubes, 8 (66.67\%) items were unavailable which were sizes $2.0 \mathrm{~mm}, 3.0 \mathrm{~mm}$ and $4.0 \mathrm{~mm}$ uncuffed and $3.0 \mathrm{~mm}, 3.5 \mathrm{~mm}, 4.0 \mathrm{~mm}, 8.0 \mathrm{~mm}$ and $8.5 \mathrm{~mm}$ cuffed. They had at least one (1) KY jelly tube and one (1) $10 \mathrm{ml}$ syringe, no tape of plaster and $5(62.5 \%)$ oropharyngeal airways were available which were sizes 000, 00, 0, 2 and 3 and 3 (37.5\%) were unavailable which were sizes 1, 4 and 5, while Ante-Natal Care Hospital A: were in possession of a laryngoscope scope set, but no spare battery or spare bulbs. Tracheal tubes: 3 (25\%) items were available which sizes were $2.5 \mathrm{~mm}$ uncuffed and $3.5 \mathrm{~mm}$ and $7.0 \mathrm{~mm}$ cuffed sizes, 9 (75\%) items were unavailable which were sizes $2.0 \mathrm{~mm}, 3.0 \mathrm{~mm}, 3.5 \mathrm{~mm}$ and $4.0 \mathrm{~mm}$ uncuffed and $3.0 \mathrm{~mm}, 4.0 \mathrm{~mm}, 7.5 \mathrm{~mm}, 8.0 \mathrm{~mm}$ and $8.5 \mathrm{~mm}$ cuffed. One (1) KY jelly tube and one (1) $10 \mathrm{ml}$ syringe was available, no tape of plaster was available, and only $2(25 \%)$ oropharyngeal airways were available. Sizes which were 000 and 00.6 (75\%) of the airways were not available.

Ante-Natal Ward Hospital B: were in possession of laryngoscope set with spare bulbs and batteries, Tracheal tubes: 3 (25\%) items were available which were sizes $7.0 \mathrm{~mm}, 7.5 \mathrm{~mm}$ and $8.0 \mathrm{~mm}$ cuffed et tubes, 9 (75\%) were unavailable which were $2.0 \mathrm{~mm}, 2.5 \mathrm{~mm}, 3.0 \mathrm{~mm}, 3.5 \mathrm{~mm}$ and $4.0 \mathrm{~mm}$ uncuffed and 2.5 $\mathrm{mm}, 3.0 \mathrm{~mm}, 3.5 \mathrm{~mm}, 4.0 \mathrm{~mm}, 4.5 \mathrm{~mm}$ and $8.5 \mathrm{~mm}$ et tubes. One (1) tube of $\mathrm{KY}$ 
jelly and one (1) $10 \mathrm{ml}$ syringe were available, and one (1) tape of plaster was available. Oropharyngeal airways $4(50 \%)$ were available in sizes 1, 2, 3 and 4 , however $4(50 \%)$ were unavailable which were sizes $000,00,0$ and 5 while Ante-Natal Ward Hospital A: were in possession of laryngoscope set, but no spare bulbs and batteries. Tracheal tubes: 6 (50\%) items were available which were sizes $2.5 \mathrm{~mm}, 3.0 \mathrm{~mm}$ and $4.0 \mathrm{~mm}$ uncuffed and $7.0 \mathrm{~mm}, 8.0 \mathrm{~mm}$ and 8.5 $\mathrm{mm}$ cuffed et tubes. $6(50 \%)$ items were unavailable $2.0 \mathrm{~mm} 3.5 \mathrm{~mm}$ uncuffed and $3.0 \mathrm{~mm}, 3.5 \mathrm{~mm}, 4.0 \mathrm{~mm}$ and $7.5 \mathrm{~mm}$ et tubes. One (1) tube of KY jelly and one (1) $10 \mathrm{ml}$ syringe were available, and no tape of plaster was available. Oropharyngeal airways $6(75 \%)$ were available in sizes $000,00,0,1,2$, and 4 , however $2(25 \%)$ were unavailable which were sizes 3 and 5.

Post-Natal Ward Block A Hospital B: were in possession of laryngoscope set, spare bulbs and batteries. Tracheal tubes: 5 (41.67\%) items were available which were sizes $2.0 \mathrm{~mm}, 2.5 \mathrm{~mm}$ and $3.0 \mathrm{~mm}$ uncuffed and $7.0 \mathrm{~mm}$ and $8.0 \mathrm{~mm}$ cuffed et tubes. 7 (58.33\%) items were unavailable sizes $3.5 \mathrm{~mm}$ and $4.0 \mathrm{~mm}$ uncuffed and $3.0 \mathrm{~mm}, 3.5 \mathrm{~mm}, 4.0 \mathrm{~mm}, 7.5 \mathrm{~mm}$ and $8.5 \mathrm{~mm}$ cuffed et tubes. One (1) tube of KY jelly and one (1) $10 \mathrm{ml}$ syringe were available, and no tape of plaster was available. Oropharyngeal airways $6(75 \%)$ were available in sizes $000,00,0,2,3$, and 4, however 2 (25\%) were unavailable which were sizes 1 and 5. Post-Natal Ward B Hospital B: were in possession of laryngoscope set, but no functioning batteries or spare bulbs and spare batteries. Tracheal tubes: 2 (16.67\%) items were available which were sizes $7.0 \mathrm{~mm}$ and $7.5 \mathrm{~mm}$ cuffed et tubes. 10 (83.33\%) items were unavailable sizes $2.0 \mathrm{~mm}, 2.5 \mathrm{~mm}, 3.0 \mathrm{~mm}, 3.5 \mathrm{~mm}$ and $4.0 \mathrm{~mm}$ uncuffed and $3.0 \mathrm{~mm}, 3.5 \mathrm{~mm}, 4.0 \mathrm{~mm}, 8.0 \mathrm{~mm}$ and $8.5 \mathrm{~mm}$ cuffed et tubes. One (1) tube of KY jelly and one (1) $10 \mathrm{ml}$ syringe were available, and no tape of plaster was available. Oropharyngeal airways $3(37.50 \%)$ were available in sizes 2 , 3 , and 4 . However, $5(62.50 \%)$ were unavailable which were sizes 000, 00, 0, 1 and 5 while Post-Natal Ward Central Hospital were in possession of laryngoscope set, spare bulbs and batteries. Tracheal tubes: 2 (16.67\%) items were available which were sizes $7.0 \mathrm{~mm}$ and $8.0 \mathrm{~mm}$ cuffed et tubes. 10 (83.33\%) items were unavailable sizes $2.0 \mathrm{~mm}, 2.5 \mathrm{~mm}, 3.0 \mathrm{~mm}, 3.5 \mathrm{~mm}$ and $4.0 \mathrm{~mm}$ uncuffed and $3.0 \mathrm{~mm}, 3.5 \mathrm{~mm}, 4.0 \mathrm{~mm}, 7.5 \mathrm{~mm}$ and $8.5 \mathrm{~mm}$ cuffed et tubes. no tube of $\mathrm{KY}$ jelly available. One (1) $10 \mathrm{ml}$ syringe was available, and no tape of plaster. Oropharyngeal airways $5(62.50 \%)$ were available in sizes $000,1,2,3$, and 4 . However, 3 (37.50\%) were unavailable which were sizes 00,0 and 5.

Hi-Care Unit Hospital A: is an exclusively adult unit, as such only adult components of the checklist were assessed. They were in possession of laryngoscope set, spare bulbs and batteries. Tracheal tubes: $3(75 \%)$ items were available which $7.0 \mathrm{~mm}, 7.5 \mathrm{~mm}$ were and $8.0 \mathrm{~mm}$ cuffed ET tubes. One (1) (25\%) item was unavailable sizes $8.5 \mathrm{~mm}$ cuffed ET tubes. One (1) tube of KY jelly and one (1) 10 $\mathrm{ml}$ syringe were available, and no tape of plaster was available. Oropharyngeal airways 2 (66.67\%) were available in sizes 3 and 4. However, one (1) (33.33\%) was unavailable which was size 5 . Prem Unit Hospital B: is an exclusively neo- 
natal ward, as such only neonatal components of the checklist were assessed. They were in possession of laryngoscope set, spare bulbs and batteries. Tracheal tubes: 5 (41.67\%) items were available which were sizes $2.0 \mathrm{~mm} 2.5 \mathrm{~mm}$ and 3.0 $\mathrm{mm}, 3.5 \mathrm{~mm}$ and $4.0 \mathrm{~mm}$ uncuffed et tubes. 8 (58.33\%) items were unavailable sizes $4.0 \mathrm{~mm}$ uncuffed and $3.0 \mathrm{~mm}, 3.5 \mathrm{~mm}$ and $4.0 \mathrm{~mm}$ cuffed et tubes. One (1) tube of KY jelly and one (1) $10 \mathrm{ml}$ syringe were available, and no tape of plaster was available. Oropharyngeal airways: 3 (100\%) were available in sizes 000, 00, and 0. Neonatal Intensive Care Unit Hospital A: being an exclusively specialist neonatal unit, as such only neonatal components of the checklist were assessed. It was in possession of a laryngoscope set with spare bulbs and batteries, Tracheal tubes: 4 (50\%) items were available which were sizes $2.0 \mathrm{~mm}, 3.0 \mathrm{~mm}, 3.5$ $\mathrm{mm}$, and $4.0 \mathrm{~mm}$ uncuffed available. 4 (50\%) items were unavailable which were $2.5 \mathrm{~mm}$ uncuffed and $3.0 \mathrm{~mm}, 3.5 \mathrm{~mm}$ and $4.0 \mathrm{~mm}$ cuffed were unavailable. One (1) KY jelly tube and one (1) $10 \mathrm{ml}$ syringe were available. One (1) plaster tape was available. 3 (100\%) oropharyngeal airways 000, 00, 0 were available.

\subsubsection{Equipment for Intubation Process}

The equipment for intubation process includes introducers for ET tubes, Magill's forceps, and laryngeal blades.

Ante-Natal Care Hospital B: was in possession of introducer, there was a Magill's forceps, and 3 (50\%) laryngoscope blades 1 - 3 were available, while 3 (50\%) blade numbers 0,4 and 5 was unavailable while Ante-Natal Care Hospital A: had no introducers, no Magill's forceps, and they only had 2 (33.33\%) laryngoscope blades numbers 2 and 4, while 4 (66.67\%) blades numbers $0,1,3$ and 5 were unavailable.

Ante-Natal Ward Hospital B: there was an ET tube introducer, they had a Magill's forceps and 4 (66.67\%) laryngoscope blades numbers 1 - 4, while 2 (33.33\%) blades numbers 0 and 5 were unavailable while Ante-Natal Ward Hospital A: they were in possession of an ET tube introducer as well as Magill forceps present and 3 (50\%) laryngoscope blades numbers 1, 2 and 3 were present while 3 (50\%) blade number 0,4 and 5 was unavailable.

Post-Natal Ward Block A Hospital B: there was no ET tube introducers, there were Magill's forceps, and 4 (66.67\%) laryngoscope blades numbers 1, 2, 3 and 4 were present while $2(33.33 \%)$ blade numbers 0 and 5 were unavailable. Post-Natal Ward Block B Hospital B: were in possession of an ET tube introducers. They had a Magill's forceps and 5 (83.33\%) laryngoscope blades numbers 1 - 5 were present while 1 (16.67\%) blade number 0 was unavailable while Post-Natal Ward Hospital A: were not in possession of any ET tube introducers. They had Magill's forceps and 5 (83.33\%) laryngoscope blades numbers 1 - 5 were present while 1 (16.67\%) blade number 0 was unavailable.

$\mathrm{Hi}$-Care Hospital A: were not in possession of any ET tube introducers. They had Magill's forceps and 4 (66.67\%) laryngoscope blades numbers 1 - 4 while 2 (33.33\%) blade numbers 0 and were unavailable Prem Unit Hospital B: was not in possession of any ET tube introducers. They had Magill's forceps and 2 
(100\%) laryngoscope blades size 0 and 1 which were the standard sizes for the neonatal unit. Neonatal Intensive Care Unit Hospital A: As a neonatal unit, only the neonatal size components were assessed. They had ET tube introducers, Magill's forceps and 1 (50\%) laryngoscope blade number 1 present while 1 (50\%) blade number 0 was unavailable.

\subsubsection{Devices to Deliver Oxygen and to Ventilate Patients}

The devices to deliver oxygen and to ventilate patients include bag valve ventilation devices/AmbuBag, oxygen masks, oxygen supply.

Ante-Natal Care Hospital B: this unit was in possession of 2 (66.67\%) AmbuBags, in which one (1) was adult sized and one (1) paediatric sized. However, there was 1 (33.33\%) AmbuBag missing which was neonatal size. Oxygen delivery devices: 1 (33.33\%) device of this component was present i.e. simple face masks while $2(66.67 \%)$ devices of this component were unavailable i.e. nebulizer masks and nasal prongs. The unit had oxygen supply and tubing without a flow regulator while Ante-Natal Care Hospital A: was in possession of 2 (66.67\%) AmbuBags. One (1) was paediatric sized and one (1) neonatal sized. However, there was one (1) (33.33\%) AmbuBag missing which was adult size. Oxygen delivery devices: 1 (33.33\%) device of this component was present i.e. simple face masks while 2 (66.67\%) devices of this component were unavailable i.e. nebulizer masks and nasal prongs. The unit had oxygen supply and tubing with a flow regulator.

Ante-Natal Ward Hospital B: this unit was in possession of 2 (66.67\%) AmbuBags. One (1) was adult sized and one (1) paediatric sized. However, there was $1(33.33 \%)$ AmbuBag missing which was neonatal size. Oxygen delivery devices: $1(33.33 \%)$ aspect of this component was present i.e. simple face masks while 2 (66.67\%) aspects of this component was unavailable i.e. nebulizer masks and nasal prongs. The unit had oxygen supply and tubing without a flow regulator while Ante-Natal Ward Hospital A: was in possession of 1 (33.33\%) AmbuBag. This was adult sized but was used as it was no longer in sterile packaging. 2 (66.67\%) AmbuBags were missing which were neonatal size and paediatric size. Oxygen delivery devices: 2 (66.67\%) aspect of this component were present i.e. simple face masks and nebulizer mask, while 1 (33.33\%) aspect of this component was unavailable i.e. nasal prongs. The unit had no oxygen supply cylinder and tubing with no a flow regulator.

Post-Natal Ward Block A Hospital B: this unit was in possession of 2 (66.67\%) AmbuBags. One (1) was adult sized and one (1) paediatric sized, however there was one 1 (33.33\%) AmbuBag missing which was neonatal size. Oxygen delivery devices: $2(66.67 \%)$ aspect of this component were present i.e. simple face masks and nasal prongs, while 1 (33.33\%) aspect of this component was unavailable i.e. nebulizer masks. The unit had no oxygen supply tubing and no flow regulator. Post-Natal Ward Block B Hospital B: this unit was in possession of $2(66.67 \%)$ AmbuBags. One (1) was adult sized and one (1) paediatric sized, however there was 1 (33.33\%) AmbuBag missing which was neonatal size. Oxygen delivery de- 
vices: $1(33.33 \%)$ aspect of this component was present i.e. simple face masks while $2(66.67 \%)$ aspects of this component were unavailable i.e. nebulizer masks and nasal prongs. The unit had no oxygen supply tubing and no flow regulator while Post-Natal Ward Hospital A: was in possession of 1 (33.33\%) AmbuBag. This was adult sized but was used as it was no longer in sterile packaging. 2 (66.67\%) AmbuBags were missing which were neonatal size and paediatric size. Oxygen delivery devices: 2 (66.67\%) aspect of this component were present i.e. simple face masks and nebulizer mask, while 1 (33.33\%) aspect of this component was unavailable i.e. nasal prongs. The unit had no oxygen supply cylinder and tubing with no a flow regulator.

Hi-Care Hospital A: this exclusively adult ward was subject to only adult specifications. This unit was in possession of $1(100 \%)$ AmbuBag which was adult sized. Oxygen delivery devices: 2 (66.67\%) aspect of this component were present i.e. nebulizer masks and nasal prongs, while 1 (33.33\%) aspect of this component was unavailable i.e. simple face masks. The unit had oxygen supply and tubing with a flow regulator. Prem Unit Hospital B: Being an exclusively neonatal unit, Prem unit was only subject to neonatal and paediatric sizes. This unit was in possession of $2(100 \%)$ AmbuBags. One (1) was paediatric sized and the other neonatal sized. It was also in possession of a modern neonatal resuscitator which is used in the place of the AmbuBag. Oxygen delivery devices: 2 (66.67\%) aspect of this component were present i.e. simple face masks and nasal prongs, while 1 (33.33\%) aspect of this component was unavailable i.e. nebulizer masks. The unit had oxygen supply and tubing with a flow regulator. Neonatal Intensive Care Unit Hospital A: being an exclusively neonatal unit. Prem unit was only subject to neonatal and paediatric sizes. This unit was in possession of 2 (100\%) AmbuBags. One (1) was neonatal sized and one (1) paediatric sized. It was also in possession of a modern neonatal resuscitator which is used in the place of the AmbuBag. Oxygen delivery devices: 1 (33.33\%) aspect of this component was present i.e. nebulizer mask, while $2(66.67 \%)$ aspects of this component was unavailable i.e. simple face mask and nasal prongs. The unit had oxygen supply and tubing with a flow regulator

\subsubsection{Equipment to Diagnose and Treat Cardiac Dysrhythmias}

The equipment to diagnose and treat cardiac dysrhythmias includes ECG monitor defibrillator and cardiac arrest board.

Ante-Natal Care Hospital B: was not in possession of an ECG monitor defibrillator. It, however, did have a cardiac arrest board which was found hanging on the size of the emergency trolley while Ante-Natal Care Hospital A: was not in possession of an ECG monitor defibrillator. It did not have a cardiac arrest board.

Ante-Natal Ward Hospital B: was in possession of an ECG monitor defibrillator which was in working order. It had a cardiac arrest board which was found hanging on the size of the emergency trolley while Ante-Natal Ward Hospital A: was not in possession of an ECG monitor defibrillator. It did not have a cardiac 
arrest board.

Post-Natal Ward Block A Hospital B: was not in possession of an ECG monitor defibrillator. It however did have a cardiac arrest board which was not found hanging on the size of the emergency trolley. Post-Natal Ward Block B Hospital B: was not in possession of an ECG monitor defibrillator. It, however, did have cardiac arrest board which was found hanging on the size of the emergency trolley while Post-Natal Ward Hospital A: was not in possession of an ECG monitor defibrillator. It did not have a cardiac arrest board.

$\mathrm{Hi}$-Care Hospital A: was in possession of an ECG monitor defibrillator which was in working order. It did not have a cardiac arrest board. Prem Unit Hospital B: was not in possession of an ECG monitor defibrillator. It did not have a cardiac arrest board which is usually found hanging on the side of the emergency trolley. Neonatal Intensive Care Unit Hospital A: was not in possession of an ECG monitor defibrillator. It did not have a cardiac arrest board

\subsubsection{Devices to Gain Intravascular Access}

The devices to gain intravascular access include I.V. cannulae, needles, syringes, sharps container, I.V. administration sets.

Ante-Natal Care Hospital B: the ward was in possession of adequate amount of intravenous cannulae, injection needles, syringes and intravenous administration sets. It however did not have a sharps container while Ante-Natal Care Hospital A: was in possession of adequate amount of intravenous cannulae, injection needles, syringes and intravenous administration sets. It however did not have a sharps container.

Ante-Natal Ward Hospital B: the ward was in possession of adequate amount of intravenous cannulae, injection needles, syringes and intravenous administration sets. It also had a sharps container while Ante-Natal Ward Hospital A: was in possession of adequate amount of intravenous cannulae, injection needles, syringes and intravenous administration sets. It, however, did not have a sharps container.

Post-Natal Ward Block A Hospital B: the ward was in possession of adequate amount of intravenous cannulae, injection needles, syringes and intravenous administration sets. It, however, did not have a sharps container. Post-Natal Ward Block B Hospital B: the ward was in possession of adequate amount of intravenous cannulae, injection needles, syringes and intravenous administration sets. It, however, did not have a sharps container while Post-Natal Ward Hospital A: was in possession of adequate amount of intravenous cannulae, injection needles, syringes and intravenous administration sets. It also had a sharps container.

$\mathrm{Hi}$-Care Hospital A: the ward was in possession of adequate amount of intravenous cannulae, injection needles, syringes and intravenous administration sets. It also had a sharps container. Prem Unit Hospital B: the ward was in possession of adequate amount of intravenous cannulae, injection needles, syringes 
and intravenous administration sets. It also had a sharps container. Neonatal Intensive Care Unit Hospital A: the ward was in possession of adequate amount of intravenous cannulae, injection needles, syringes and intravenous administration sets. It also had a sharps container.

\subsubsection{Equipment to Monitor Airway, Breathing and Circulation}

The equipment to monitor airway, breathing and circulation include stethoscope, pulse oximeter, non-invasive blood pressure monitoring device, thermometer, blood glucose testing, and collection tubes for investigation.

Ante-Natal Care Hospital B: they were in possession of a stethoscope, pulse oximeter, non-invasive BP monitoring, thermometer, blood glucose testing and collection tubes for investigation while Ante-Natal Care Hospital A: were not in possession of a stethoscope. They had a pulse oximeter, non-invasive BP monitoring, thermometer, blood glucose testing and collection tubes for investigation.

Ante-Natal Ward Hospital B: they were not in possession of a stethoscope. They had a pulse oximeter, non-invasive BP monitoring, thermometer, blood glucose testing and collection tubes for investigation while Ante-Natal Ward Hospital A: were not in possession of a stethoscope. They had a pulse oximeter, non-invasive BP monitoring, thermometer, blood glucose testing and collection tubes for investigation.

Post-Natal Ward Block A Hospital B: they were not in possession of a stethoscope. They had a pulse oximeter, non-invasive BP monitoring, thermometer, blood glucose testing and collection tubes for investigation. Post-Natal Ward Block B Hospital B: they were not in possession of a stethoscope. They had a pulse oximeter, non-invasive BP monitoring, thermometer, blood glucose testing and collection tubes for investigation. While Post-Natal Ward Hospital A: were in possession of a stethoscope; however the stethoscope was not in functioning order. They had a pulse oximeter, non-invasive BP monitoring, thermometer, blood glucose testing and collection tubes for investigation.

$\mathrm{Hi}$-Care Hospital A: they were not in possession of a stethoscope. They had a pulse oximeter, non-invasive BP monitoring, thermometer, blood glucose testing and collection tubes for investigation. Prem Unit Hospital B: they were in possession of a stethoscope, pulse oximeter, thermometer and blood glucose testing and collection tubes for investigation. Because this was a neonatal unit, they were not in possession of a non-invasive BP monitoring machine. Neonatal Intensive Care Unit Hospital A: they were not in possession of a stethoscope, pulse oximeter, thermometer and blood glucose testing and collection tubes for investigation. Because this was a neonatal unit, they were not in possession of a non-invasive BP monitoring machine.

\subsubsection{Appropriate Hardware}

The appropriate hardware of the various units and wards included heavy duty scissors to cut clothing, drip stand, suction devices and suction catheters, universal precautions and patella hammer.

Ante-Natal Care Hospital B: they were in possession of all items in this aspect 
of the emergency trolley checklist which included heavy duty scissors, drip stand, suction devices and catheters, universal precautions, and patella hammer while Ante-Natal Care Hospital A: were not in possession of either heavy duty scissors, drip stand, universal precautions or patella hammer. They however were in possession of suction devices.

Ante-Natal Ward Hospital B: they were in possession of heavy duty scissors, suction devices and catheters, universal precautions, and patella hammer. However, they did not have a drip stand while Ante-Natal Ward Hospital A: was not in possession of heavy duty scissors, but they did have a drip stand, suction devices and catheters, universal precautions and patella hammer.

Post-Natal Ward Block A Hospital B: the ward was not in possession of heavy duty scissors, but they did have a drip stand, suction devices and catheters, universal precautions and patella hammer. Post-Natal Ward Block B Hospital B: the ward was not in possession of heavy duty scissors, but they did have a drip stand, suction devices and catheters, universal precautions and patella hammer while Post-Natal Ward Hospital A: were in possession of all items in this aspect of the emergency trolley checklist which included heavy duty scissors, drip stand, suction devices and catheters, universal precautions, and patella hammer.

Hi-Care Hospital A: the ward was not in possession of heavy duty scissors, but they did have a drip stand, suction devices and catheters, universal precautions and patella hammer. Prem Unit Hospital B: the ward was not in possession of heavy duty scissors, but they did have a drip stand, suction devices and catheters, universal precautions, because they are a neonatal units, they did not have a need for a patella hammer. Neonatal Intensive Care Unit Hospital A: the unit was not in possession of heavy duty scissors. They were in possession of drips stands, suction devices and catheter and universal precaution. The unit is a neonatal unit and as such were not in need of a patella hammer.

\subsubsection{Miscellaneous}

The miscellaneous items of the various units and wards include medication stickers, resuscitation algorithms and resuscitation documentation records.

Ante-Natal Care Hospital B: they were not in possession of any of the aspects of this component which were medication stickers, resuscitation algorithms or resuscitation documentation records while Ante-Natal Care Hospital A: were not in possession of any of the aspects of this component which were medication stickers, resuscitation algorithms or resuscitation documentation records.

Ante-Natal Ward Hospital B: they were not in possession of any of the aspects of this component which were medication stickers, resuscitation algorithms or resuscitation documentation records while Ante-Natal Ward Hospital A was in possession of some resuscitation algorithms such as which emergency drugs is necessary for which condition. They, however, did not have any algorithms in cardiopulmonary resuscitation. They were not in possession of either medication stickers or resuscitation documentation records.

Post-Natal Ward Block A Hospital B: they were not in possession of any of the 
aspects of this component which were medication stickers, resuscitation algorithms or resuscitation documentation records. Post-Natal Ward Block B Hospital B: they were not in possession of any of the aspects of this component which were medication stickers, resuscitation algorithms or resuscitation documentation records while Post-Natal Ward Hospital A was in possession of some resuscitation algorithms such as the emergency drugs is necessary for which condition. They, however, did not have any algorithms in cardiopulmonary resuscitation. They were not in possession of either medication stickers or resuscitation documentation records.

Hi-Care Hospital A: they were not in possession of any of the aspects of this component which were medication stickers, resuscitation algorithms or resuscitation documentation records. Prem Unit Hospital B: they were not in possession of any of the aspects of this component which were medication stickers, resuscitation algorithms or resuscitation documentation records. Neonatal Intensive Care Unit Hospital A: they were not in possession of any of the aspects of this component which were medication stickers, resuscitation algorithms or resuscitation documentation records.

\subsection{Evaluate the Availability of Essential Emergency Resuscitation Drugs}

\section{Objective 2: Evaluate the availability of essential emergency resuscitation drugs}

This topic discusses the availability of essential emergency resuscitation drugs that were present or absent in the various wards and units as well as whether they were still usable expired. They are as follows.

\subsubsection{Essential Drugs}

The assessment of the essential drugs component was done on the merit of an individual unit and ward basis. This is because many of the wards had additional drugs added to their emergency depending on the type of emergency that commonly occurred there. Units like Neonatal Intensive Care Unit only had certain drugs that the other wards had however they also had other drugs added like Phytonadione as the unit had instances whereby they would need these drugs. Units like the Ante-Natal Care Hospital A had added Nifedipine for pregnant women that presented with high blood pressure while none of the other wards had this medication on the emergency trolley. This tool was standardized and adjusted to meet the assessment need of the different units and wards.

\section{Hospital B}

Ante-Natal Care Of the 24 drugs assessed in the emergency trolley 21 were present in the emergency trolley. However, of the 21 present about 3 of the drugs were expired. The expired drugs were Hydrocortisone, Atrovent and Sodium Bicarbonate $4 \%$. Two (2) out of the four (4) the dextrose $50 \%$ had become a yellowish colour and thus defective. Ante-Natal Ward of the 25 drugs assessed, only 20 were present in the emergency trolley. Digoxin had expired on 09/17, as well 
as sodium bicarbonate $4 \%$ on $09 / 17$. Post-Natal Ward Block A: of the 24 drugs assessed, only 20 of the items were available. Of these that were available sodium bicarbonate expired on the 09/17. Post-Natal Ward Block B: of the 25 drugs assessed, only 19 were available in the emergency trolley. Prem Unit: of the 23 drugs assessed in this unit, only 17 were available in the emergency trolley. Of these 17 available, 3 of these drugs had expired. These were Digoxin and sodium bicarbonate $4 \%$ on the $09 / 17$ and potassium chloride on the $08 / 17$.

\section{Hospital A}

Ante-Natal Care: of the 25 emergency drugs assessed in the emergency trolley, 11 were present. 1 of the missing drugs had been ordered. Ante-Natal Ward Hospital A: of the 31 emergency drugs assessed in the emergency trolley of the ward, 25 of the drugs were present in the trolley. Of those that were present, 2 items were expired. They were Magnesium Sulphate and Digoxin. Post-Natal Ward: of the 27 emergency drugs assessed in the emergency trolley, 18 of them were present. Of those that were present, 2 were expired which were digoxin and naloxone $0.4 \mathrm{mg} / 1 \mathrm{ml}$ on the 09/17. HI-CARE: of the 28 drugs assessed in this unit, 24 of the drugs were present in the drug drawer of the emergency trolley. Neonatal Intensive Care Unit: Of the 20 drugs assessed in the emergency trolley, 18 were present.

\subsubsection{Intravenous Solutions}

The intravenous solutions of the various units and wards were presented as follows.

\section{Hospital B}

Ante-Natal Care: of the 7 IV solutions assessed, 4 were present. 3 were however absent; Ante-Natal Ward: of the 7 IV solutions assessed, 1 was present only. 6 were absent. Post-Natal Ward Block A: of the 7 IV solutions assessed, 4 were present. Post-Natal Ward Block B: of the 7 IV solutions assessed, 5 were present. Prem Unit: of the 6 IV solutions, 2 were present.

\section{Hospital A}

Ante-Natal Care: of the 7 IV solutions assessed, 5 were present while in Ante-Natal Ward: of the 7 IV solutions assessed, 2 were present. In the Post-Natal Ward: of the 7 IV solutions assessed, 0 were present. This was a shocking finding and highly unacceptable for a ward to score this badly. Hi-Care: of the 8 IV solutions assessed, 6 were present. However, 2 were expired on 06/17. Neonatal Intensive Care Unit: of the 6 IV solutions assessed, 5 were present. However, 3 were expired on $07 / 17$

\subsection{Assessment of the Condition and Functionality of the Emergency Trolley}

\section{Objective 3: Assess the condition and functionality of the emergency trolley}

This topic discusses the condition and functionality of the emergency trolley in the various units and wards, whether they were in working order, whether they were appropriate, if they were really emergency trolley. They are further 
discussed and are as follows.

\section{Hospital B}

Ante-Natal Care: the emergency trolley was in a good condition. It was mobile and accessible. The emergency trolley was however obstructed by an examination bed and benches. It was not central in the unit, but was found in the far end of the unit in a side room. This was not appropriate for where an emergency trolley should be placed. It should ideally be placed in the centre of the unit. Another profound assessment was that the drawer that houses the emergency drugs was broken open by force. Ante-Natal Ward: the emergency trolley was in a good condition, it was clean and well maintained. The locks were functioning and the keys were present. The emergency trolley was mobile and accessible. It was however obstructed by other trolleys and boxes. It was ideally located in the centre of the ward. Post-Natal Ward Block A: the general condition of the emergency trolley was good. It was well maintained, clean and neat. It was mobile, unobstructed and accessible. It was ideally located in the centre of the ward. Its locks were in a working order and functioning well. Post-Natal Ward Block B: the general condition of the emergency trolley was good. It was well maintained, clean and neat. The top of the emergency trolley was well organised. It was mobile, unobstructed and accessible. It was ideally located in the centre of the ward. Its locks were in a working order and functioning well. Prem Unit: the emergency trolley was need, well packed and well organised. It was accessible and appropriately locked in the resuscitation room of the unit. It was mobile and found right next to the OHIO used for neonatal resuscitation.

\section{Hospital A}

Ante-Natal Care: this unit was not in possession of an emergency trolley. They were forced to use a food trolley as a make shift emergency trolley. However, the Registered nurse ensured that this food trolley was well stocked, need and had the bare minimums for emergency resuscitation. It was, however, not good enough as multiple components were missing from this food trolley. It potential hindered efforts to reduce maternal and infant mortality, and violated the rights of the patient and the efforts of nursing staff in rendering effective and efficient nursing care. Ante-Natal Ward: the emergency trolley was unorganised, the top was poorly organised. The trolley was a newer model than those found at Hospital B. They emergency trolley was found in the delivery room of the ward which is in the far end of the ward. It was not ideally located in a central area of the ward. Post-Natal Ward: the emergency trolley was very poorly managed as the top of the trolley was not neat, disorganised and the sharps container was full to the brim. The trolley was ideally located in the centre of the ward. It was unobstructed and accessible. It was mobile. It was a newer model emergency trolley Hi-Care: this was one (1) of the neatest emergency trolleys assessed. It was also the only emergency trolley in the maternity section of the Hospital A that had an ECG monitor defibrillator. It was well located in the unit, it was accessible, unobstructed and was mobile. It was well organised. Neonatal Intensive Care Unit: this unit was also in possession of a newer model emergency trolley. It was very 
neat, well organised, well managed and clean. It was located in the Intensive care section of the unit. It was accessible, unobstructed and mobile.

\subsection{Assessment of the Records of the Emergency Trolleys}

This focusses on the checklist used by the units and wards provided by the various department managers. It was to assess whether these checklists were used, how often they were used and whether the entries corresponded with what was available and are as follows.

\section{Hospital B}

Ante-Natal Care: the records were audited on the 01/09/17. The trolley was not assessed on that day or the day before that. In fact, the emergency trolley records were not assessed since the 17/08/17. Ante-Natal Ward: the records were audited on the $01 / 09 / 17$. The trolley was not assessed on that day or the day before that. There was no consistency in the checking of the contents. The checklist was done sporadically. Post-Natal Ward Block A: the records were audited on the $01 / 09 / 17$. The trolley was not assessed on that day but was assessed the day before that. It was observed that there was a repetition of how the checklist was ticked as even though certain equipment was not fully replenished, it was ticked as present Post-Natal Ward Block B: the records were audited on the 01/09/17. The trolley was not assessed on that day, but it was assessed the day before that. There was no consistency in the checking of the contents. The checklist was ticked sporadically. There were multiple days when the contents were not assessed e.g. 10, 11, 19 and 29/08/17. Prem Unit: the records were audited on the $01 / 09 / 17$. The emergency trolley record checklist was ticked on the present day as well as the day before.

\section{Hospital A}

Ante-Natal Care: this unit was not in possession of an emergency trolley. They were using a food trolley as a make shift emergency trolley. It was therefore difficult to assess the records of this unit. Ante-Natal Ward: the records were audited on the 15/09/17. The trolley was not assessed on that day or the day before that. In fact, there was no consistency in the daily checking of the emergency trolley contents. The contents were not assessed from the 1/09 to the 15/09/17. Post-Natal Ward: the records were audited on the 18/09/17. The contents were not assessed on the present day or the previous day. There was no consistency in the checking of the contents as the last assessment was done on the 15/09/17 and only certain aspects were assessed.

Hi-Care: the records were audited on the 15/09/17. The contents were assessed on the present day or the previous day. There was consistency in the checking of the contents of the emergency trolley. Neonatal Intensive Care Unit: The records were audited on the 18/09/17. The contents were assessed on the present day. However, it was not assessed on the previous day. There was no consistency in the daily checking of the contents of the emergency trolley.

Overall performace of the unit or ward in the audit of the emergency contents is in the maternity section of the state hospitals in Windhoek, Namibia. 




Figure 1. Overall performance of units and wards at Hospital A and B.

Figure 1 illustrates the overall score the unit or ward received for the various aspects that were assessed.

With the assessment of the overall score, the $\mathrm{n}$ value was used to divide the overall items available in each ward or unit and multiplied by 100. This was to come to the percentage score for each unit and ward. All the units and wards of both state hospitals were able to score above $50 \%$. The highly specialized units i.e. Hi-Care, Neonatal Intensive Care Unit and Prem Unit were able to score well within the $70 \%$ range and these were the units that scored the best for the overall performance assessment. Neonatal Intensive Care Unit did exceptionally well as many of their components were present. The Ante-Natal Care Hospital A scored the lowest out of all the units and wards. This was because their emergency trolley was in fact a food trolley used as a makeshift emergency trolley. This caused them to score consistently low with the assessments done.

\section{Discussion of the Findings}

To my knowledge this was the first study aimed at assessing and evaluating emergency equipment, drugs and the emergency trolleys at the maternity sections of the state hospitals in Windhoek, Namibia. With an increase in the number of women bearing children especially those within Windhoek, there is an increase in need for the maternity section in the Windhoek state hospitals to be adequately prepared for managing emergencies. Studies have shown that very often emergency equipment and drugs are not readily available during emergency management and resuscitations [8]. This study has further highlighted and emphasized the great need for a checklist that is standardized but also specified for each unit and ward. Due to the lack of certain emergency equipment, drugs and functional emergency trolleys in certain units and wards, it was questionable whether they could effectively and efficiently manage patients during emergency resuscitative efforts. A survey conducted by The Pennsylvania Patient Safety Authority [9] indicated common issues relating to emergency equipment availability, including missing items, incorrect equipment sizes, empty oxygen tanks, drained batteries, un-stocked or unlocked emergency trolleys and failure to identify expired items. In addition it emphasized how crucial it is for manag- 
ing bodies to decide on the level of care necessary for a particular practice and to have an appropriate written plan for the checking and provision of emergency equipment and drugs. Successful advanced life support relies, in part, upon the availability and correct functioning of resuscitation equipment. However, numerous publications report deficiencies and defects in key items of resuscitation equipment, particularly those relating to airway management and defibrillation. Some of these are human error (notably, inadequate knowledge, lack of experience and training, inadequate checking, insufficient maintenance). However, others are device specific. This study not only highlights the lack of standardization of emergency items and designated responsibility towards delivery, maintenance and refurbishment after use but also the areas where they units and wards have had successes such as the location of where most of the emergency trolleys are located. The maternity sections of the state hospitals in Windhoek provide a high volume service and any delay may lead to considerable maternal and infant morbidity and mortality. Primary healthcare centres appear to lack the training and equipment to manage common paediatric emergencies. We recommend standardization of equipment and algorithms, training and assessment of key personnel, and critical incident reporting within primary healthcare centres [10]. As with in the primary health care, the paediatric equipment in the maternity sections including bag valve mask devices, Magill's forceps, oxygen masks were found to be absent in many of the units and wards. Specifically designed paediatric emergency trolleys have been shown to optimize the outcome of paediatric resuscitation. Colour coding has also been associated with a significant reduction in errors in emergency drugs dosages and equipment use. Emergency trolleys should also be equipped with appropriate equipment. Early defibrillation improves the outcome of patients presenting in cardiac arrest for every minute's delay in defibrillation, survival decreases by $7 \%-15 \%$. The defibrillator plays a central role in patients presenting with shockable arrest rhythms (VF and pulseless VT); however, to have the maximum impact on patient outcomes, defibrillation must be done quickly and correctly. Selecting the correct Joule setting is an essential component of this process. This may lead to unnecessary delays or incorrect dosages and adversely affect survival [11]. It is evident from the data described that checking of defibrillators, monitors and suction devices still remains a major problem in the units and wards that are fortunate enough to have the aforementioned equipment. According to [12], the efficacy of emergency drugs declines beyond the expiry date which could render optimal management of emergencies to be inadequate. Adrenaline is considered a vital drug that should be available at all levels of health care and can be prescribed by any competent health care practitioner [13]. Main resuscitative drugs such as adrenaline and atropine were found to be expired at some centres. In addition to checking the availability of emergency drugs, expiry date checks should be included. Not all emergency drugs as indicated by the EMSSA checklists were found to be present, those that were not applicable to the various units and 
wards were removed from the checklist, and those that were in the emergency trolley but were not on the checklist were added in order to avoid errors.

Emergency trolley checklists should accompany the emergency trolley. EMSSA recommends regular checking on a daily basis or even more than that depending on the clinical setting. All 10 units and wards that were assessed were in possession of a checklist. The recording of emergency trolley checklists and stocking of essential equipment and drugs were found to be incongruent and inconsistent. Emergency trolleys were also not uniform at the different hospitals however they were uniform within the individual hospital units and wards. A minimum of one emergency trolley was present, with the site being well designated and easily accessible as indicated by [14]. This study raises important questions regarding in service and university training in the aspect of checking emergency trolleys. It also questions the knowledge of nurses especially the RNs in terms of their understanding of the contents of emergency trolleys and the importance of maintaining a state of readiness in the unit and ward. There needs to be more stringent accountability for checking, ordering and replacing of stock, and is an issue that needs to be addressed. Regular clinical audits by the Sister in charge or the ward managers are required, ensuring correct checking, replacing and repairing of defective items. These audits would serve as a tool to improve resource allocation and optimize emergency outcomes. Recording of resuscitation events and regular morbidity and mortality meetings are recommended. The quality of emergency resuscitative events in Namibia is an area that has been ignored for decades there needs to be an emphasis on improving emergency services in the state health services of the Republic.

\section{Limitation of the Study}

The following limitation was experienced by the researcher and may have contributed to some shortfalls in the study and the reported findings.

There was resistance experienced by the researcher in the Post Natal Ward of the Hospital A when attempting to audit the emergency trolley and upon attempting to give back feedback on certain aspects that may need improvement to certain Registered Nurses. The study was only done within the maternity sections of the state hospital in Windhoek, Namibia and could thus only be generalised to the maternity sections. The study was heavily dependent on my own knowledge and skills with regards to testing the various emergency equipments and my ability to check the drugs and emergency trolley records. I made every effort to familiarize myself with the emergency trolley records as well as the common emergency drugs they usually stock.

A study of this nature was never conducted in the Republic of Namibia before, therefore the researcher found it difficult to compare as to what was done before. If this study is a reflection of the preparation and availability of emergency equipment and drugs in the maternity sections of the state hospitals in Windhoek then there is a reason for great concern regarding quality emergency resus- 
citation efforts. It was of great concern to find expired drugs. It was concerning to find certain emergency trolley with no vacoliters at all. It was concerning to find certain emergency trolleys going unassessed for more than 15 days. There needed to be a revision of emergency guidelines and protocols and group discussion with senior registered nurses with various nurses involved in the daily running of the ward to find out what the shortcomings may be and were improvements need to be done. The senior registered nurses also need to praise units and wards that performed well. There was no standardized tool of assessment. However the checklist tool was adapted to the various wards and units to make it more specific in the data collection process.

\section{Recommendations}

The following recommendations were made in relation to the objectives of the study and are as follows.

Nursing education: Development of policy guidelines with regards to assessing, restocking and maintenance of emergency supplies, these policies can then be used to guide the nurses on what to do. Make sure nurses know where and how the emergency trolley and emergency equipment is stored as well as the content so that they are familiar with the emergency trolley and its contents as well. Resuscitation morbidity and mortality meetings in order to identify issues and outcomes surround resuscitation incidences within the unit or ward. The issues that are identified can then be used as a topic for in-service training to improve the outcome in the care that such an event does arise again.

Nursing management: Develop a ward or unit appropriate standardized checklist for the specific unit or ward. Minimization of the complexity of the emergency trolley, the addition of unnecessary equipment and itemst may be inappropriate for the ward or unit. The emergency trolley should be assessed every morning when the morning shift nurses come on duty. Daily checking of the functionality of equipment i.e. suctions devices, laryngoscope devices, ECG monitor defibrillators. Regular audits of emergency contents and records and recording of outcome are with a plan of intervention. Have references available, particularly for medications and proper medication dosages, especially for paediatric emergencies. Clearly arrange drugs in the medication drawer so that they are easy to locate and the names are clearly legible. Label the outside of the drawers that contain the various equipment and drugs. There is a need for nursing management to be more involved in this aspect of the unit and ward as to ensure that nurses assigned to the checking of the emergency trolley have an idea of what protocols to follow.

Nursing research: There is a need for a quantitative study to determine knowledge, attitudes and practises of the nurses in assessing the emergency trolley. This may better describe the short comings as to why drugs and equipment are left to expire and as to why the emergency trolley is not assessed regularly as it should be. 


\section{Conclusions}

\section{Objective 1: Evaluate the availability of essential emergency equipment}

The first objective was met. Analysis of data to evaluate the availability of essential emergency equipment was done. The data were necessary to determine if the whether there was availability of essential emergency equipment. These essential emergency equipments included: devices to open the airway, equipment for intubation process, devices to deliver oxygen and to ventilate patient, equipment to diagnose and treat cardiac dysrhythmias, devices to gain intravenous access, equipment to monitor airway, breathing and circulation, equipment to monitor airway, breathing and circulation, appropriate hardware and miscellaneous items. It was found that the majority of the wards and units at both state hospitals failed to score at least a $50 \%$ in the area of devices to protect and open the airway. This was especially so for the Ante-Natal Care Hospital A which has an extremely low score of $10 \%$ of items available for devices to open the airway. The exceptions were the specialized units such as Hi-Care, Prem Unit as well as Neonatal Intensive Care Unit which managed to score above 50\% for this component. For the aspect of equipment for intubation process, all the units and wards scored well above 50\%. The Hospital A Ante-Natal Care scored a dismal $25 \%$ while the Neonatal Intensive Care Unit Hospital A scored a significant $100 \%$ for items present. For the aspect of devices to deliver oxygen and ventilate the patient, 2 units and wards of Hospital B scored above $50 \%$ while the Ante-Natal Ward Hospital B and Post-Natal Ward Hospital A scored a dismal 28\%. The Prem Unit of Hospital B scored the highest with 83\%. In the aspect of equipment to diagnose and treat cardiac dysrhythmias, it was found that all the units had at least one (1) of the two (2) items expect for the Hospital A Ante-Natal Care and Hospital A Neonatal Intensive Care Unit. However, it was not a good scored as the adult units should at least ensure that they were in possession of an ECG monitor defibrillator. The only units and wards that were in possession of this were the Hospital B Ante-Natal Ward and Hospital A HI-Care.

In the aspect of devices to gain intravenous access, all the units and wards of both state hospitals performed well. They were able to score $80 \%$ and above. This was an excellent assessment to observe as it demonstrated that the nurses at least focused to maintain this aspect of the emergency trolley. On the aspect of equipment to monitor airway, breathing and circulation it was all the units scored exceptionally well. The only item that majority of the units and wards of both state hospitals were missing was a stethoscope. Hospital B Prem Unit and Ante-Natal Care scored $100 \%$ as well as Post-Natal Ward Hospital A. In the aspect of appropriate hardware, it was found that both hospitals scored well above $70 \%$. The only exceptions were the Hospital A Ante-Natal Care and Ante-Natal Ward that scored a dismal 20\%. The low score for Hospital A Ante-Natal Care was their lack of a proper emergency trolley. In the aspect of miscellaneous items all the units and wards of both state hospitals did extremely badly. They were lacking resuscitation forms, algorithms and medication stickers. This was truly 
an aspect that needed drastic improvements. According to [13], the equipment in the general wards and units were low compared to the specialized units like the ICU. The Neonatal Intensive Care Unit Hospital A scored consistently better than most of the other units and wards. [15] further stated that hospitals in Australia did not store their emergency trolleys properly and did not maintain their resuscitation equipment properly. The same applied to some of the units and wards in Hospital B and Hospital A like the Hospital B Ante-Natal Ward which had an emergency trolley obstructed by objects such as boxes. [16] stated that the $\mathrm{CHCs}$ did have resuscitation algorithms but they were not up to date. The majority of the units and wards that were assessed had either inadequate algorithms or had none at all. This corresponded with other studies that were done before.

Objective 2: Evaluate the availability of essential emergency resuscitation drugs

It was found that the units and wards of both state hospitals assessed generally performed well in this assessment. Most of it scored $80 \%$ and above. This was a good indication of the readiness of the units and ward for an emergency situation. However, there was room for improvement as this aspect needed a $100 \%$ score as lifesaving drugs are highly important during resuscitative efforts. It was necessary to mention that the Hospital A Neonatal Intensive Care Unit did exceptionally well in this assessment scoring $90 \%$ which was the overall best. Scores such as these needed to be praised by the unit manager. Once more the Ante-Natal Care Hospital A scored poorly with a score of $44 \%$. This was mainly due to the fact that their emergency trolley was a food trolley. According to [16], the CHCs assessed had an average of $80 \%$ of the drugs assessed. This result was also similar with the units and wards assessed in my study. It was further found that the main resuscitative drugs i.e. adrenaline and atropine were present in all CHCs expect for one where it had expired by a few months. The units and wards were all in possession of the main resuscitative drugs and they were all unexpired and present. Intravenous fluids were found in most of the trolleys. It was, however, very shocking to find that the Hospital A Post-Natal Ward was not in possession of any IV fluids on the emergency trolley. This would greatly hamper resuscitative efforts especially in patient in need of urgent IV fluids.

Objective 3: Assess the condition and functionality of the emergency trolley

The majority emergency trolleys were all accessible and unobstructed. However, the emergency trolleys of KSH Ante-Natal Care AND Ante-Natal Ward were obstructed either by benches, beds or other trolleys.

Of the five (5) emergency trolleys assessed at the Hospital A, all the emergency trolleys were unobstructed and accessible in all 5 units and wards. No was obstructed by any other item or object. This was a good assessment.

\section{References}

[1] Adamson, K. (2012) Are We Ready for an Emergency? 
http://scholar.sun.ac.za/handle/10019.1/97212

[2] Assessment-module.yale.edu. (2017) Protocol Design-Inclusion and Exclusion Criteria. Yale Assessment Module Training.

http://assessment-module.yale.edu/human-subjects-protection/protocol-design-incl $\underline{\text { usion-and-exclusion-criteria }}$

[3] Citolino Filho, C.M., Santos, E.S., Silva, R.D.C.G.E. and Nogueira, L.D.S. (2015) Factors Affecting the Quality of Cardiopulmonary Resuscitation in Inpatient Units: Perception of Nurses. Revista da Escola de Enfermagem da USP, 49, 907-913. https://doi.org/10.1590/S0080-623420150000600005

[4] Dyson, E. and Smith, G. (2002) Common Faults in Resuscitation EquipmentGuidelines for Checking Equipment and Drugs Used in Adult Cardiopulmonary Resuscitation. Resuscitation, 55, 137-149. https://doi.org/10.1016/S0300-9572(02)00169-7

[5] Emergency Medicine Society of South Africa (2008) Resuscitation Trolley Equipment. Emergency Medicine Society of South Africa. http://emssa.org.za/documents/em006.pdf

[6] Finn, J. and Jacobs, I. (2003) Cardiac Arrest Resuscitation Policy and Practice: A Survey of Western Australian Hospitals.

https://www.researchgate.net/publication/237609536_Cardiac_arrest_resuscitation policy_and_practice_A_survey_of_Western_Australian_hospitals

[7] Gnanalingham, M., Harris, G. and Didcock, E. (2006) The Availability and Accessibility of Basic Paediatric Resuscitation Equipment in Primary Healthcare Centres: Cause for Concern? Acta Paediatrica, 95, 1677-1679. https://doi.org/10.1080/08035250600763034

[8] Louw, P., Maritz, D. and Wallis, L. (2010) Emergency Centres lack of Defibrillator Knowledge. SAMJ, 100, 435-436. https://doi.org/10.7196/SAMJ.4107

[9] Mahfouz, A. and Abdelmoneim, I. (2017) Primary Health Care Emergency Services in Abha District of Southwestern Saudi Arabia. Eastern Mediterranean Health Journal, 13, 103-112. https://www.ncbi.nlm.nih.gov/pubmed/17546912

[10] Maritz, D., Hodkinson, P. and Wallis, L. (2010) Identification of Performance Indicators for Emergency Centres in South Africa: Results of a Delphi Study. International Journal of Emergency Medicine, 3, 341-349. https://doi.org/10.1007/s12245-010-0240-6

[11] Office of Rural and Remote Health (2012) Queensland Health. Ministry of Health. https://www.health.qld.gov.au/rrcsu/docs/rress_G2_resustrolley.pdf

[12] Pennsylvania Patient Safety Advisory (2017) Clinical Emergency: Are You Ready in Any Setting? http://patientsafety.pa.gov/ADVISORIES/Documents/201006_52.pdf

[13] Rajeswaran, L. and Ehlers, V.J. (2012) Audits of Emergency Trolleys' Contents in Selected Hospitals in Botswana. Health SA Gesondheid, 17, 7. https://doi.org/10.4102/hsag.v17i1.621

[14] Research Rundowns (2017) Instrument, Validity, Reliability. https://researchrundowns.com/quantitative-methods/instrument-validity-reliability/

[15] Rossiter, D. (2012) South African Medicines Formulary. 10th Edition, Health \& Medical Publishing Group, Rondebosch.

[16] World Health Organisation (2018) NEMLIST_Namibia Essential Medicines List. 6th Edition. http://apps.who.int/medicinedocs/en/m/abstract/Js23017en/ 